\title{
$=\mathrm{T} R A M A=$
}

\section{APONTAMENTOS PARA O ENSINO DO SISTEMA SONORO DO PB}

\author{
Adelaide Hercília Pescatori Silva (UFPR) ${ }^{1}$
}

\begin{abstract}
RESUMO: Este artigo visa a contribuir para o ensino de português brasileiro (PB) como língua estrangeira. Para tanto, segue dois argumentos: o de que a língua é um sistema adaptativo complexo - o que implica a necessidade de se conspirarem variáveis extralinguísticas no processo de ensinoaprendizagem em interação com variáveis linguística - e o de que é preciso conhecer a estrutura fonético-fonológica do PB e da língua materna dos aprendizes, para que se possa desenvolver uma abordagem próxima à realidade desses aprendizes. Para embasar tais argumentos, lançamos mão de dados português brasileiro produzidos por falantes nativos de crioulo haitiano e analisados acusticamente.
\end{abstract}

PALAVRAS-CHAVE: Fonética. Análise acústica. Sistemas adaptativos complexos. Crioulo haitiano. Português como língua estrangeira.

ABSTRACT: This paper aims to contribute to the teaching of Brazilian Portuguese (PB) as a foreign language. In order to do so, it follows two arguments: that language is a Complex Adaptive System which implies the need to recognize extralinguistic variables in the teaching-learning process interacting with linguistic ones - and that it is necessary to know the sound structure of $B P$, as well as the sound structure of the apprentices' mother tongue, so that an approach that is close to the reality of these learners can be developed. To support such arguments, we analyzed acoustically Brazilian Portuguese data produced by native speakers of Haitian Creole.

KEYWORDS: Phonetics. Acoustic analysis. Complex adaptative systems. Haitian Creole. Portuguese as a foreign language.

\section{INTRODUÇÃO}

A demanda crescente por reflexões e por material didático de ensino de português como língua estrangeira (PLE) ${ }^{2}$, me faz crer cabível uma modesta contribuição para o ensino do nível sonoro do português brasileiro (PB) a migrantes, em especial haitianos. A razão pela escolha específica dos migrantes haitianos se justifica pelo fato de ainda haver um contingente expressivo deles no país. De 2010 até 2017, a estimativa é de que mais de 70 mil haitianos tenham chegado ao Brasil.

Além da presença maciça de haitianos no país, uma outra razão para o foco sobre estes migrantes está na escassez de estudos linguísticos sobre o crioulo haitiano - doravante referido como "kreyòl"- uma língua que tem o francês como base lexical e cuja base gramatical provém principalmente das línguas ewe, fon e iorubá, segundo Tardieu (2013). Descrições linguísticas sobre o crioulo haitiano, cabe frisar, são escassas na literatura linguística em geral, não apenas no Brasil. Logo, compreender o funcionamento do kreyòl, além de auxiliar na criação de

\footnotetext{
${ }^{1}$ Professora Titular do Departamento de Literatura e Linguística da Universidade Federal do Paraná, interessase, particularmente, pela análise acústica dos sons da fala e pela integração entre fonética e fonologia. E-mail: adelaidehpsilva@gmail.com

2 Embora a literatura registre termos distintos para referir-se ao português adquirido por falantes nativos de outras línguas, como "português para falantes de outras línguas", "português como língua de acolhimento", "português como língua adicional", não é objeto deste estudo a discussão sobre as diferenças epistemológicas subjacentes a cada um dos termos. Por isso, escolhi o termo "português como língua estrangeira" apenas por me parecer mais genérico que os demais.
} 


\section{$=$ TRAMA $=$}

ferramentas para o ensino do PB para haitianos, pode igualmente trazer contribuições para a compreensão do funcionamento dessa língua.

Justificado o foco sobre o kreyòl, devo esclarecer que este estudo tenta cumprir o objetivo a que se propõe - a saber, oferecer uma pequena contribuição para o ensino de PB a migrantes haitianos - seguindo dois eixos argumentativos centrais: o de que é preciso pensar em métodos que focalizem o ensino de PB para falantes nativos de uma língua específica, ao invés de se criar métodos genéricos de ensino de PB, e o de que as línguas podem ser concebidas como Sistemas Adaptativos Complexos (SACs), o que implica concebê-las como fatos resultantes da interação entre variáveis de naturezas diversas, como pretendo explicitar no decorrer deste estudo. Os dois eixos argumentativos encontram respaldo empírico nos dados de produção do PB, colhidos junto a falantes nativos de kreyòl e analisados acusticamente, que serão apresentados mais adiante neste estudo. Cabe acrescentar, além disso, que este estudo assume a associação entre Fonética e Fonologia, ou seja, abandona-se a perspectiva inaugurada no Estruturalismo linguístico, e segundo a qual Fonética e Fonologia são disciplinas independentes. À luz de modelos dinâmicos de produção da fala, como a Fonologia Acústico-Articulatória (ALBANO, 2001), assumimos ser impossível fazer Fonologia sem recorrer à Fonética e vice-versa.

Assim sendo, este estudo se organiza da seguinte maneira: a próxima seção traz considerações sobre a necessidade de se elaborar um material de ensino de PLE específico para falantes nativos de kreyòl. Na seção seguinte, ofereço uma breve abordagem das línguas como sistemas adaptativos complexos. Na sequência, apresento a análise acústica dos dados de fala de haitianos que vivem no Brasil e adquirem o PB. Finalmente, a última seção traz uma discussão dos dados à luz das escolhas epistemológicas e metodológicas apresentadas nas seções iniciais.

\section{POR QUE ELABORAR UM MATERIAL DE ENSINO DE PLE ESPECIIFICO PARA UMA LÍNGUA?}

Este estudo segue a proposta de Alves, Brisolara e Perozzo (2017), que oferecem um método de ensino de pronúncia dos sons do PB específico para hispanofalantes. Para os autores, tal especificidade se coaduna com a perspectiva de apresentar o nível sonoro do PB a aprendizes dentro de um contexto comunicativo de ensino. Os autores seguem o Modelo de Ensino Comunicativo de Pronúncia, proposto por Celce-Murcia et al. (2010), e que é composto por cinco etapas: 1) descrição e análise, que requer a explicação dos detalhes formais da língua a ser aprendida; 2) discriminação auditiva, que deve proporcionar aos aprendizes distinguir os sons entre si; 3) prática controlada, que consiste na prática de repetição e de leitura de palavras ou sentenças, para que o aprendiz possa automatizar os sons da língua que está adquirindo; 4) prática guiada, que consiste na seleção de uma tarefa com estruturas que devam ser utilizadas pelo aprendiz; 5) prática comunicativa, que objetiva fazer com que o aprendiz expresse eu ponto de vista sobre o tópico abordado na aula. É uma atividade mais livre que as demais se se aproxima de um ambiente de comunicação real. Nela, se espera que o aprendiz pratique o que aprendeu durante a aula.

No que diz respeito especialmente ao primeiro aspecto - descrição e análise - que requer que o professor explicite os aspectos da língua a ser aprendida ${ }^{3}$, e considerando que o Modelo de Ensino Comunicativo de Pronúncia deve possibilitar a discriminação auditiva, como

\footnotetext{
${ }^{3}$ Algumas distinções estabelecidas na literatura de línguas estrangeiras não serão seguidas à risca neste estudo, porque ele não objetiva discutir tais distinções. É o caso da distinção que a literatura estabelece entre "aprendizado" e "aquisição" de uma língua. Tampouco se discutirá o conceito de inteligibilidade, já que ele sequer tem uma definição clara na literatura da área, como evidência Becker (2013).
} 


\section{$=$ TRAMA $=$}

etapa seguinte à descrição e análise de aspectos da língua-alvo ${ }^{4}$, e como maneira de propiciar a inteligibilidade e compreensibilidade na produção oral, é importante que se focalizem sobretudo os aspectos da língua-alvo que podem causar dificuldade para falantes nativos de uma dada língua. Dentre esses aspectos, encontram-se sons que a língua-alvo tem, mas a língua materna dos aprendizes, não.

Assim, por exemplo, Silva (2015) apresenta o quadro consonantal do kreyòl, em comparação com o quadro consonantal do PB, e nota que, embora os inventários de consoantes sejam muito parecidos em ambas as línguas, o kreyòl não tem o tap alveolar [r], presente em palavras como "arara", no PB. Como resultado da ausência dessa consoante, e com base em autores como Major (2008), pode-se esperar que os falantes nativos de kreyòl transfiram para o PB a ausência dessa consoante e produzam, em seu lugar, a lateral alveolar [1]. Presente em PB em palavras como "aleluia", a lateral alveolar é muito próxima do tap em termos articulatórios - ambas são articuladas no ponto alveolar e ambas pertencem à classe das líquidas. Porém, a "troca" prevista do tap pela lateral alveolar nas produções de PB pelos haitianos pode gerar problemas de inteligibilidade e compreensibilidade em sua fala, já que em PB as duas consoantes são distintivas, i.e., promovem diferença de sentido entre palavras quando intercambiadas, em pares como "cala/cara"; "ela/era"; "pula/pura"; "colo/coro5". Observe-se que, como este fato não acontece em todas as línguas - o espanhol, por exemplo, faz a mesma distinção que o PB - um aspecto do nível sonoro que necessita ser trabalhado com falantes nativos de uma língua não precisa ser tratado quando se trabalha com falantes nativos de outra língua.

Uma observação parentética necessária: embora muitos brasileiros acreditem que os haitianos falem francês fluente, essa afirmação precisa ser relativizada, pois segundo Cadely (2012), os haitianos que falam francês constituem uma parcela diminuta da população e são restritos àqueles que aprenderam francês na escola. Logo, muitos dos haitianos que chegam ao Brasil, em particular as mulheres, falam apenas kreyòl.

Voltando às considerações sobre o sistema sonoro do kreyòl e do português, cabe mencionar que outro exemplo de diferença entre os dois sistemas está no acento lexical: enquanto ele é imprevisível no PB, é completamente previsível no kreyòl, provavelmente uma "herança" do francês, de modo que as palavras apresentam o acento lexical, ou primário, via de regra, na última sílaba. Como resultado, e de acordo com Silva (2015), os falantes nativos de kreyòl tendem a produzir as palavras do PB com acento primário na última sílaba. Também essa diferença pode causar problemas de inteligibilidade e compreensibilidade na língua-alvo, já que o PB diferencia, pelo lugar do acento lexical, palavras como "pia" e "piá6".

Dadas estas diferenças entre o sistema sonoro do kreyòl e o sistema sonoro do PB, e dada a perspectiva teórica que embasa a proposta de Alves et al. (2017) que sigo neste estudo, deve ficar clara a necessidade de se conceber um método de ensino de pronúncia de PB voltado aos falantes nativos de kreyòl. Ou seja, em razão das especificidades da estrutura da língua materna de um grupo de aprendizes de PLE, não se pode empregar o método que Alves et al. (op.cit.), por exemplo, propõem para o ensino de PB a hispanofalantes. Afinal, a diferenciação entre a consoante fricativa alveolar desvozeada [s] e a consoante fricativa alveolar vozeada [z], que os hispanofalantes não fazem e precisa ser adquirida por eles, já que

\footnotetext{
${ }^{4}$ Chamo de língua-alvo, neste estudo, à língua que está sendo adquirida. No contexto das reflexões aqui apresentadas, a língua-alvo é o português brasileiro.

${ }^{5}$ Primeira pessoa do singular do presente do indicativo dos verbos "colar" e "corar", respectivamente.

6 Forma utilizada na região Sul do Brasil e que significa "menino", "garoto".
} 


\section{$=$ TRAMA $=$}

é distintiva no $\mathrm{PB}^{7}$, é um problema que simplesmente não se coloca para os falantes nativos de kreyòl, que realizam a diferenciação. Ao mesmo tempo, a diferença entre o tap alveolar [r] e a lateral alveolar [I] que fazemos no PB não se aplica aos hispanofalantes, que também a produzem, mas é fundamental para os falantes nativos de kreyòl. Em resumo, quando se trata de ensino de pronúncia, é de suma importância o estudo comparativo entre os sistemas sonoros da língua materna dos aprendizes e da língua-alvo, de modo que se possam prever as principais dificuldades desses aprendizes e, ao mesmo tempo, elaborar um método de ensino tais dificuldades sejam abordadas, como requer o Modelo de Ensino Comunicativo de Pronúncia, proposto por Celce-Murcia et al. (2010).

Feitas estas considerações, a próxima seção trata da concepção de língua como um Sistema Adaptativo Complexo (SAC), o segundo eixo argumentativo deste estudo.

\section{LÍNGUA COMO SISTEMA ADAPTATIVO COMPLEXO}

A concepção de língua como Sistema Adaptativo Complexo (SAC) é uma posição nova na literatura linguística, que surge no final da primeira década deste século e que se apresenta como uma concepção de língua promissora, já que a literatura tem oferecido fartas evidências empíricas para a interrelação entre os elementos linguísticos, quando se considera a produção da fala. Este ponto merece ser esclarecido e é este o caminho que o texto percorre em sua sequência.

Chan (2001) nota que "a complexidade resulta da interrelação, interação e interconectividade dos elementos dentro de um sistema e entre um sistema e seu ambiente ${ }^{8 "}$. Nesse sentido, os Sistemas Adaptativos Complexos são sistemas dinâmicos, que podem se adaptar e se desenvolver com a mudança do ambiente. A mesma autora observa que, como decorrência da interação entre o sistema e seu ambiente, não se prevê uma separação entre ambos; ao contrário, preconiza-se que os sistemas se adaptem a um ambiente em mudança. Esta mudança, por sua vez, implica a evolução do sistema. (É necessário notar, aliás, que a evolução, aqui, é concebida nos termos darwinianos, ou seja, uma "descendência com modificações", o que não implica, forçosamente, que a evolução traga melhora ao sistema.)

São características de um Sistema Adaptativo Complexo:

1) controle distribuído, que implica a ausência de um controle central único do sistema a determinar seu comportamento. Consequentemente, não se pode prever o comportamento de todo o sistema a partir do comportamento das partes que o constituem;

2) conectividade dos elementos dentro de um sistema e entre sistemas, que traz como resultado o fato de que uma ação de uma parte do sistema influenciará todas as partes relacionadas, embora não de maneira uniforme;

3) co-evolução, que implica em que os elementos num sistema podem mudar em razão de suas interações com outros elementos do mesmo sistema e com o ambiente. Além disso, os padrões de comportamento dos elementos podem mudar em função do tempo;

4) dependência sensível das condições iniciais, que remete ao fato de que mudanças no input do sistema não se correlacionam linearmente com os resultados desse sistema. Como consequência da falta de correlação linear, pequenas mudanças podem ter um impacto profundo sobre o comportamento geral do sistema, ao passo que grandes perturbações podem

\footnotetext{
${ }^{7}$ Assim, por exemplo, [s] e [z] operam distinção de sentido em início de sílaba e palavra, como no par "selo"/ "zelo" e operam distinção de sentido em início de sílaba, no meio de palavra, como no par "caço"/ "caso". Note que, neste último par, as consoantes do meio das palavras são, respectivamente, [s] e [z].

${ }^{8}$ No original: "Complexity results from the inter-relationship, inter-action and inter-connectivity of elements within a system and between a system and its environment." Chan (2001:1) (Tradução é minha).
} 


\section{$=$ TRAMA $=$}

não afetar o sistema. (A ilustração prototípica para esta característica de um SAC são os sistemas meteorológicos).

5) ordem emergente, ou dinâmica emergente. Para explicar esta característica, recorrer a um exemplo talvez seja mais fácil. Imagine um grupo de pessoas reunidas em torno de um jogo de tabuleiro, e.g., War. O jogo tem uma série de regras, que determinam como os jogadores devem proceder para atingir o objetivo de dominar territórios. Cada jogador traça uma estratégia de ação, mas um determinado jogador mudará sua estratégia caso note que um oponente adota uma estratégia que prejudica seu plano inicial. Ele reelaborará sua estratégia visando a atingir seu objetivo. Essa mudança configura a ordem, ou dinâmica, emergente de um SAC;

6) distância do equilíbrio. Embora os SACs tendam a recuperar seu equilíbrio, ao se distanciarem dele, a distância do equilíbrio pode ser um fator importante para a sobrevivência e o desenvolvimento de um sistema. Se, ao contrário, o sistema se mantiver em equilíbrio, ele poderá morrer. Recentemente, um estudo norte-americano sobre a estação de pesquisa Tall Timbers, na Flórida, onde funcionava uma central de combate a incêndios florestais, revelou que, durante os quarenta anos pelos quais se estendeu o estudo, o ecossistema sofreu graves consequências, que fizeram diminuir a diversidade da flora do parque, além de levarem ao completo desaparecimento espécies de pássaros, como pica-paus ${ }^{9}$. A conclusão é de que, para sobreviver, o ecossistema necessita dos incêndios, ou seja, de distância do equilíbrio;

7) estado de paradoxo, que remete ao fato de que os sistemas dinâmicos combinam ordem e caos, estabilidade e instabilidade, ordem e desordem, competição e cooperação, ou seja, a ordem necessita do caos, para que se garanta, em última instância, a sobrevivência do SAC. Assim, é possivel que um SAC ora tenda a um estado, ora a outro.

Delineadas as características gerais de um Sistema Adaptativo Complexo, é preciso pensar como se pode conceber a língua como um tal sistema. Nesse sentido, Beckner et al. (2009) observam que a língua pode ser tomada como um sistema - assim como outros tantos paradigmas teóricos o fazem. Porém, diferentemente dos sistemas concebidos por modelos tradicionais na teoria linguística, assumir a língua como um SAC implica reconhecer que ela é um sistema constituído de múltiplos agentes, que são os falantes de uma dada comunidade de fala. Os falantes/agentes interagem entre si e, obviamente, dessa interação emerge uma dinâmica, que ora afasta, ora aproxima o sistema de um ponto de equilíbrio. O afastamento de um sistema de seu estado de equilíbrio pode ser verificado, por exemplo, nos fatos que a literatura linguística chama "mudança em curso"10. Além disso, comentam os autores, o fato de um sistema ser adaptativo se revela no comportamento dos falantes, que se baseia nas interações passadas com outros usuários da língua. Tais interações, em conjunto com as interações presentes, levam a um comportamento futuro. O comportamento dos falantes, por sua vez, resulta de fatores em competição e que se estendem desde restrições perceptuais até a motivações sociais. Além disso, as estruturas de uma língua emergem de padrões interrelacionados de experiência, interação social e mecanismos cognitivos. Desta forma, como observam Beckner et al. (op.cit.), "o tratamento de uma língua como SAC revela pontos comuns em várias áreas da pesquisa linguística, como a aquisição de primeira e segunda línguas, a

\footnotetext{
${ }_{9}^{9}$ Um relato sobre este estudo pode ser lido em https://science.howstuffworks.com/environmental/greenscience/how-forest-fire-benefit-living-things-2.htm

${ }_{10}$ Um exemplo de mudança em curso pode ser o que se verifica com os sons de /r/ do PB falado na região sul do país, onde a variante vibrante vai sendo paulatinamente substituída por uma variante fricativa posterior: Silva (2002) mostra que essas variantes co-ocorrem na fala de um mesmo indivíduo e, mais, que a variante produzida pode tender à vibrante ou tender à fricativa, a depender da força de fronteira adjacente. Tem-se, portanto, uma configuração do sistema em que ele se distancia do equilíbrio, que poderia ser tomado como a produção de uma variante específica, verificando-se a produção de variantes que reúnem em si características de vibrantes e de fricativas, mas que não são propriamente nem uma nem outra.
} 


\section{$=\mathrm{T} R A M A=$}

linguística histórica, a psicolinguística, a evolução da linguagem e o modelamento computacional ${ }^{11 "}$.

Para ilustrar a possibilidade de tratamento da língua como um SAC, passamos à análise dos dados do PB produzidos por falantes nativos de kreyòl, na próxima seção.

\section{AQUISIÇÃO DO PB POR FALANTES NATIVOS DE KREYÒL}

Começo esta seção retomando um ponto tratado ainda na segunda seção deste estudo: a comparação entre os sistemas sonoros do PB e do kreyòl, particularmente no que toca ao inventário das líquidas - sons de /r/ e sons de /// - que é o foco deste estudo, em razão da inexistência da oposição entre o tap alveolar e a lateral. O quadro a seguir traz a comparação:

\begin{tabular}{l|l|l}
\hline & \multicolumn{2}{|l}{ Sons alveolares } \\
\hline & PB & kreyòl \\
\hline tap & $\mathrm{r}$ & \\
\hline lateral & $\mathrm{I}$ & $\mathrm{I}$ \\
\hline aproximante & 1 & \\
\hline
\end{tabular}

Quadro 1- Inventário de consoantes líquidas do kreyòl cf. Cadely (2004)

Ainda segundo Cadely (2004), o kreyòl tem uma consoante fricativa posterior, que funciona como som de /r/ e pode ocorrer em grupos consonantais, por exemplo.

O quadro comparativo apresentado suscita a pergunta: ao adquirir PB, falantes nativos de kreyòl "trocarão" tap por lateral, transferindo elementos da fonologia de sua língua materna para o PB? Colocando de outra forma: haitianos que adquirem PB produzirão "alala" por "arara", ou produzirão "ela", indistintamente, para referir-se ao pronome de terceira pessoa do singular, no gênero feminino, bem como à forma de terceira pessoa do singular do pretérito imperfeito do verbo "ser"? Essa pergunta se baseia em estudos como o de Major (2008), que preconiza que, no processo de aprendizagem de uma língua estrangeira, os falantes transferem para a língua-alvo elementos da sua língua materna.

Porém, é preciso fazer algumas considerações sobre essa pergunta: ao assumir que a aquisição do nível sonoro de uma língua estrangeira se fundamenta sobre mecanismos de substituição, principalmente nos estágios iniciais desse processo, a pergunta admite um comportamento uniforme dos aprendizes, i.e., espera-se que qualquer indivíduo, ao iniciar o processo de aquisição de uma língua estrangeira, substitua um som por outro. Nesse sentido, a outra consideração que cabe fazer é que a pergunta que propusemos no início deste parágrafo concebe que um som qualquer é substituído por outro, i.e., uma categoria é inteiramente substituída por outra. Além disso, a pergunta assume a fala como um fato unimodal, ou seja, como um fato que se articula apenas através da modalidade oral, sem a complementaridade de fatos outros, como por exemplo gestos manuais ou movimentos faciais.

\footnotetext{
${ }^{11}$ No original: "The CAS approach reveals commonalities in many areas of language research, including first and second language acquisition, historical linguistics, psycholinguistics, language evolution, and computational modeling" (BECKNER et al. (2009, p. 01). (Tradução minha).
} 


\section{$=$ TRAMA $=$}

Os dados que discutiremos na sequência questionam justamente a concepção de que o processo de aquisição de uma língua estrangeira se alicerça sobre mecanismos de substituição de um som por outro e de que essa substituição envolve categorias de sons. Desta forma, começamos apresentando dados produzidos por J., com 27 anos na época da coleta dos dados. J. declarava falar francês e inglês, que aprendera na escola, tinha se graduado em Direito no Haiti, e estava no Brasil há menos de um ano. Os dados apresentados foram colhidos numa sala silenciosa, durante a tarefa de leitura da crônica "O poder ultrajovem", de Carlos Drummond de Andrade. Por se configurar uma inspeção inicial da produção deste sujeito, não se elaborou um experimento de coleta de dados de produção, propriamente. Ainda assim, os dados fornecem pistas para um experimento que se conduziu na sequência.

Examinemos, inicialmente, os dados da Figura 1, a seguir.

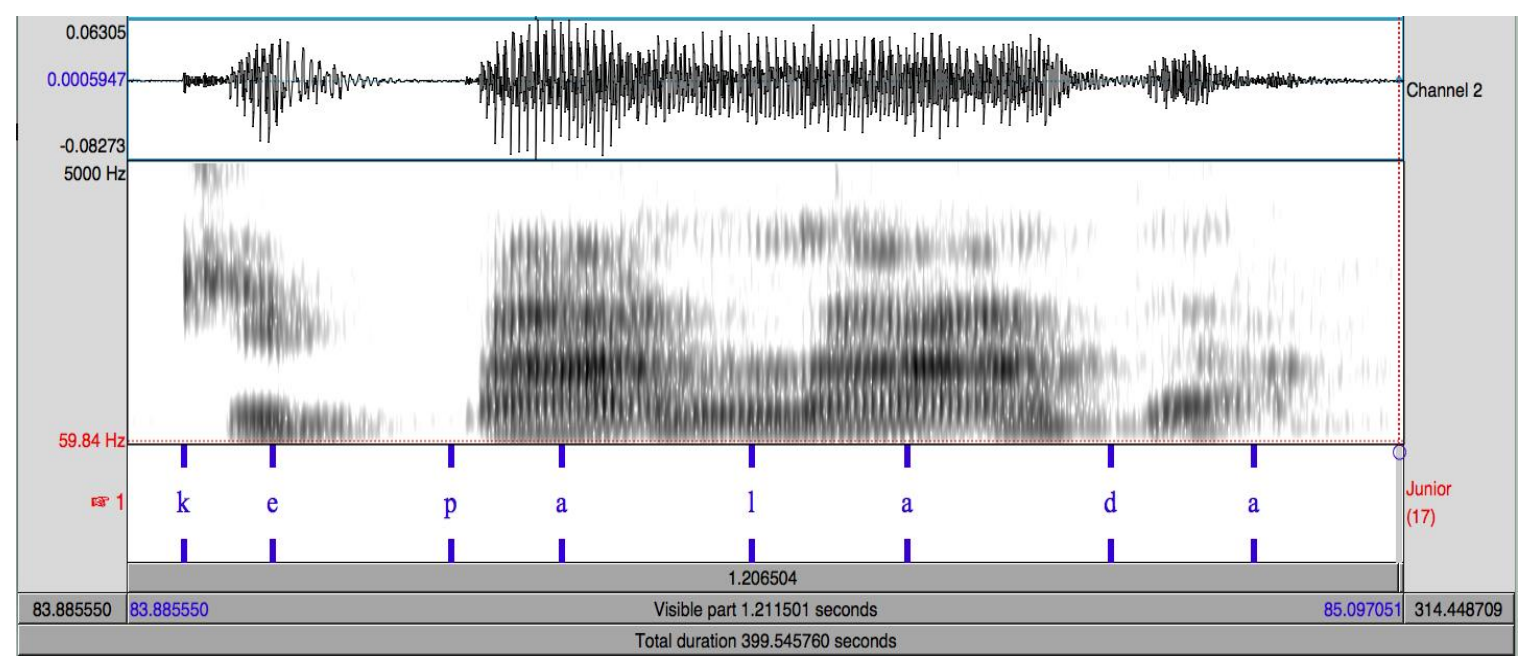

Figura 1 - Oscilograma e espectrograma da sequência "que parada", produzida por J.

Observando especialmente o espectrograma da Figura 1, alinhado a uma transcrição ortográfica da sequência, notamos que, de fato, J. substituiu o tap pela lateral, como evidencia o aspecto visual contínuo do evento acústico imediatamente acima do grafema $<1>$. Além disso, vemos também que o primeiro e o segundo formantes estão numa região baixa de frequência (a escala no canto superior esquerdo do espectrograma sugere que F2 se localiza em torno de $1000 \mathrm{~Hz}$ ), outra característica acústica da lateral alveolar [l], conforme descreve Silva (1999). F3, como se nota, está ausente no espectrograma, como ocorre frequentemente com a lateral. Passemos agora para outro dado:

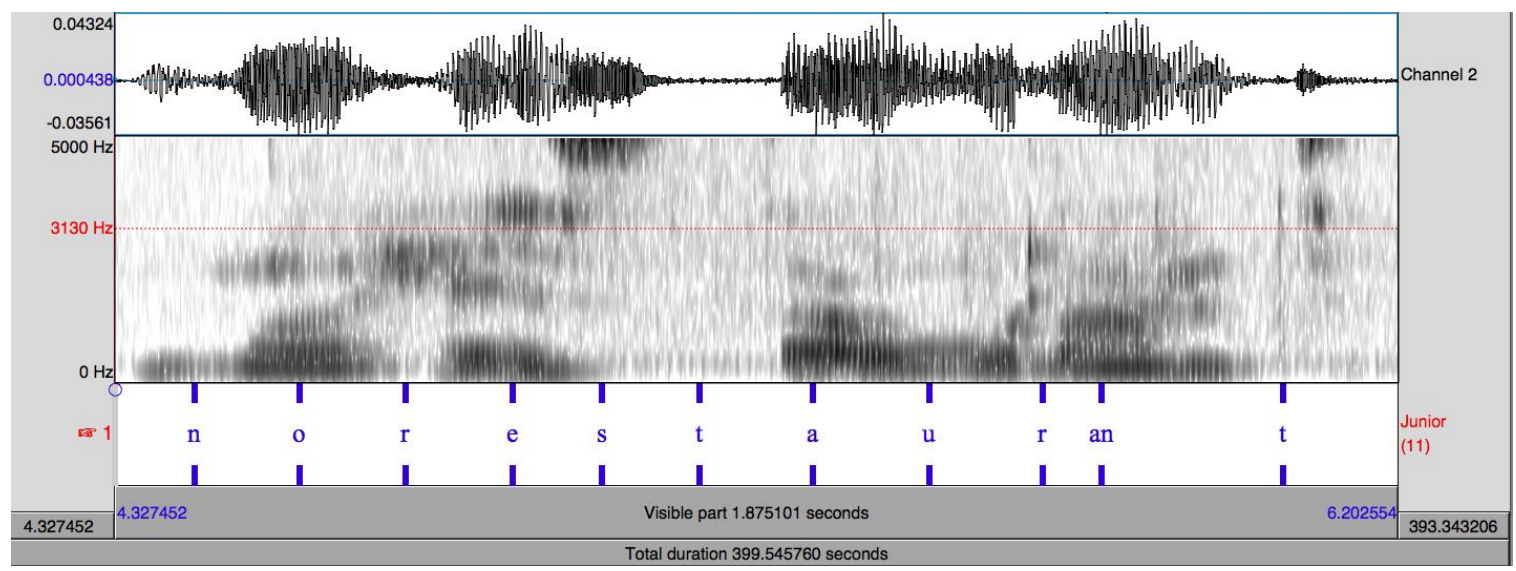

Figura 2 - Oscilograma e espectrograma da sequência "no restaurante", produzida por J. 


\section{$=$ TRAMA $=$}

Esta sequência, colhida durante a mesma tarefa de leitura em que foi colhido o dado ilustrado na Figura 1, vai em direção contrária ao que víamos ali: note que o evento acústico sobre o grafema $<r>$ ao final da sequência, entre $<u>$ e $<$ an $>$, revela-se um evento descontínuo, com uma barra vertical correspondente à soltura da oclusão com que é produzido. Além disso, é um evento muito breve. Estas são características prototípicas do tap, como mostra Silva (1999). Ou seja, J. substitui o tap pela lateral, como se vê na Figura 1, mas consegue igualmente produzir um tap, conforme se tem na Figura 2. Pode-se dizer, portanto, de uma variabilidade de produção na fala desse sujeito. E a variabilidade vai além, como ilustra a Figura 3, a seguir:

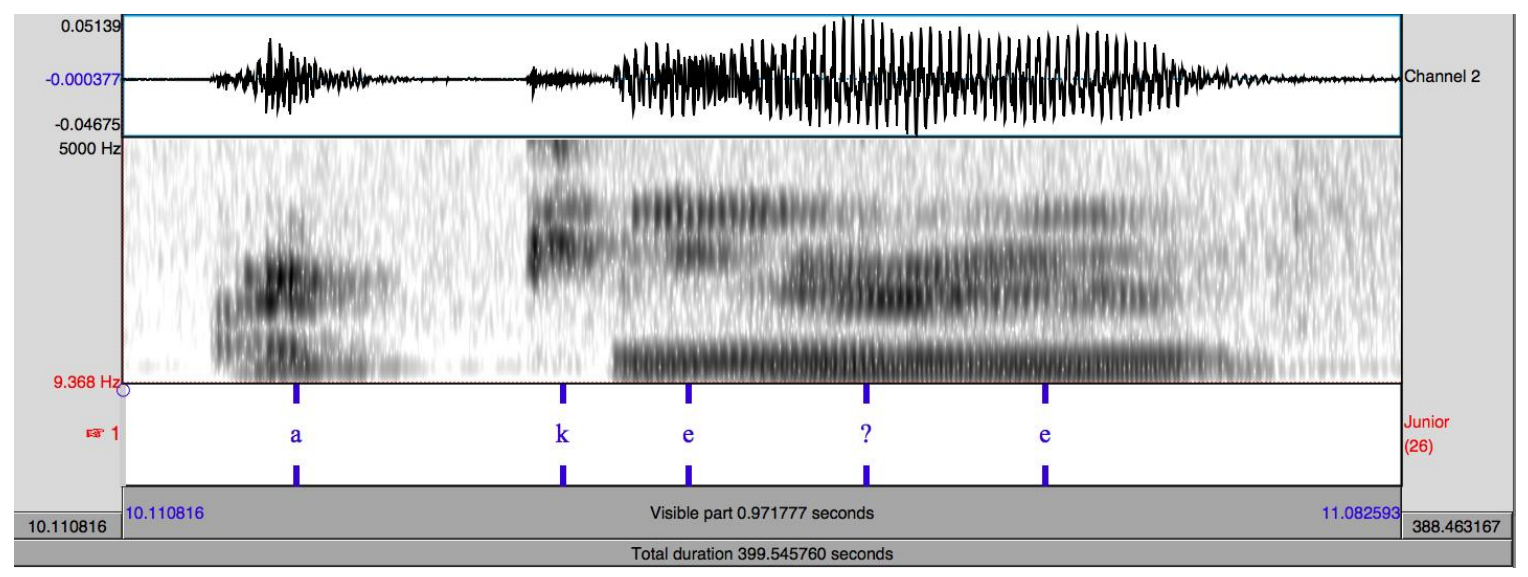

Figura 3 - Oscilograma e espectrograma da sequência "aquele", produzida por J.

Neste caso, embora o evento acústico alinhado ao ponto de interrogação tenha um aspecto visual contínuo, e não seja breve, F1 está numa região de frequência baixa no espectrograma, ao mesmo tempo em que se encontra distante de F2 e F3, localizados próximos entre si, numa região de frequência alta no espectrograma. Essa configuração dos formantes sugere que o som produzido não seja uma lateral, mas talvez uma aproximante alveolar [ $\lrcorner$ ]. Entretanto, a duração longa do evento acústico não caracteriza a duração de uma aproximante alveolar, geralmente breve. Tem-se, então, um som entre lateral e rótico, ou seja, intermediário a duas categorias.

Em suma, estes exemplos apresentados nas Figuras 1, 2 e 3 contradizem as assunções subjacentes à pergunta que colocávamos sobre a transposição das categorias sonoras da língua materna do aprendiz para a língua-alvo: não só J. consegue produzir um tap (cf. Figura 2), como produz evento acústico intermediário ao tap e à lateral (cf. Figura 3). Logo, o processo de aquisição de uma língua estrangeira parece bem mais complexo do que se configurava inicialmente, à luz da questão colocada.

Por isso, foi realizado um experimento de produção junto a outros haitianos. Desta vez, o experimento foi controlado: empregando uma narrativa curta, elaborada especificamente para o experimento, e contendo dissílabos e trissílabos paroxítonos, nos quais tap e lateral ocupavam posição intervocálica e pós-tônica. Havia, no instrumento de coleta de dados, um total de doze palavras-alvo, das quais seis continham tap e, outras seis, lateral. Os dados do experimento foram colhidos junto a quatro haitianos, alunos de um curso de ensino de Português para Falantes e Outras Línguas (PFOL), na Universidade Tecnológica Federal do Parná (UTFPR) em Curitiba. Todos os quatro sujeitos residiam no Brasil há no máximo um ano, no momento da coleta. Logo, poder-se-ia dizer que eram aprendizes de PB em nível inicial. As gravações conduzidas por um aluno de Iniciação Cientíica - foram todas feitas em cabine com tratamento 


\section{$=\mathrm{TRAMA}=$}

acústico, na UTFPR, e cada indivíduo leu três vezes a narrativa curta. O perfil de cada sujeito desse experimento era o seguinte:

- S1: sexo masculino, no Brasil há um ano e um mês na época da coleta de dados. Concluiu ensino médio no Haiti. Declarou ter aulas de PB há aproximadamente sete meses. Declarou falar francês, inglês e um pouco de espanhol;

- S2: sexo masculino, no Brasil há 10 meses na época da coleta de dados. Estudante de odontologia no Haiti. Declarou ter aulas de PB há 10 meses. Declarou falar inglês e francês;

- S3: sexo feminino, no Brasil há aproximadamente um ano e cinco meses na época da coleta dos dados. Estudante de enfermagem no Haiti. Afirmou ter aulas de PB há um ano. Declarou ter aprendido francês, inglês e espanhol na escola;

- S4: sexo feminino, no Brasil há oito meses na época da coleta dos dados. Concluiu ensino médio no Haiti. Declarou ter aulas de PB há menos de três meses. Afirmou ter aprendido francês. Demonstrou dificuldade significativa na leitura da narrativa.

Schmicheck (2018), em seu relatório de Iniciação Científica, apresentou a análise qualitativa que realizou para os dados de S1, S2 e S4. Os dados de S3 não serão reportados porque, segundo Schmicheck (2018), o sujeito produziu apenas a aproximante alveolar, em todos os estímulos. Cabe esclarecer que, em razão do número reduzido de dados, por um lado, e em razão da grande variabilidade na produção, por outro, não foi possível realizar uma análise estatística inferencial.

Outra nota necessária sobre as tabelas que se seguem: os dados estão divididos em grupos, para um mesmo sujeito. Assim, o "grupo 1" remete aos estímulos dissílabos, com tap; o "grupo 2" reúne os estímulos dissílabos, com lateral; o "grupo 3" compreende os estímulos trissílabos, com tap; o "grupo 4" contém os estímulos trissílabos, com lateral.

\begin{tabular}{|l|l|l|l|}
\hline \multicolumn{5}{|c|}{ Sujeito 1 - Grupo 1 - Dissílabos com a presença de IrI } \\
\hline Tipologia & \multicolumn{1}{|c|}{$\begin{array}{c}\text { Presença nas Trôs } \\
\text { Repetições }\end{array}$} & $\begin{array}{c}\text { Média de Duração } \\
\text { Absoluta em } \\
\text { milissegundos (ms) }\end{array}$ & $\begin{array}{c}\text { Média de Duração } \\
\text { Relativa } \\
\text { Segmento/Palavra }\end{array}$ \\
\hline Aproximantes & $66,6 \%$ & 38 & $7,8 \%$ \\
\hline Taps & $33,3 \%$ & 39 & $7,2 \%$ \\
\hline
\end{tabular}

Tabela 1 - valores obtidos para o grupo 1 do primeiro sujeito (dados de J. V. Schimicheck).

\begin{tabular}{|l|l|l|l|}
\hline \multicolumn{5}{|c|}{ Sujeito 1 - Grupo 2 - Dissilabos com a presença de /l/ } \\
\hline \multicolumn{1}{|c|}{ Tipologia } & \multicolumn{1}{|c|}{$\begin{array}{c}\text { Presença nas Três } \\
\text { Repetiçōes }\end{array}$} & $\begin{array}{c}\text { Média de Duração Absoluta } \\
\text { em milissegundos (ms) }\end{array}$ & $\begin{array}{c}\text { Média de Duração Relativa } \\
\text { Segmento/Palavra }\end{array}$ \\
\hline Aproximantes & $88,9 \%$ & 51 & $10,1 \%$ \\
\hline Taps & $11,1 \%$ & 25 & $4,5 \%$ \\
\hline
\end{tabular}

Tabela 2 - valores obtidos para o grupo 2 do primeiro sujeito (dados de J.V. Schmicheck). 


\begin{tabular}{|l|l|l|l|}
\hline \multicolumn{5}{|c|}{ Sujeito 1 - Grupo 3 - Trissilabos com a presença de /rl } \\
\hline \multicolumn{1}{|c|}{ Tipologia } & $\begin{array}{c}\text { Presença nas Três } \\
\text { Repetições }\end{array}$ & $\begin{array}{c}\text { Média de Duração Absoluta } \\
\text { em milissegundos (ms) }\end{array}$ & $\begin{array}{c}\text { Média de Duração Relativa } \\
\text { Segmento/Palavra }\end{array}$ \\
\hline Aproximantes & $55,6 \%$ & 51 & $6,9 \%$ \\
\hline Laterais & $22,2 \%$ & 84 & $11,4 \%$ \\
\hline Taps & $22,2 \%$ & 42 & $6,2 \%$ \\
\hline
\end{tabular}

Tabela 3 - valores obtidos para o grupo 3 do primeiro sujeito (dados de J.V. Schmicheck).

\begin{tabular}{|l|l|l|l|}
\hline \multicolumn{5}{|c|}{ Sujeitol 1 - Grupo 4 - Trissílabos com a presença de III } \\
\hline \multicolumn{1}{|c|}{ Tipologia } & \multicolumn{1}{|c|}{$\begin{array}{c}\text { Presença nas Três } \\
\text { Repetiçöes }\end{array}$} & $\begin{array}{c}\text { Média de Duração } \\
\text { Absoluta em } \\
\text { milissegundos (ms) }\end{array}$ & $\begin{array}{c}\text { Média de Duração Relativa } \\
\text { Segmento/Palavra }\end{array}$ \\
\hline Aproximantes & $66,7 \%$ & 65 & $8,8 \%$ \\
\hline Laterais & $22,2 \%$ & 59 & $7,9 \%$ \\
\hline Taps & $11,1 \%$ & 47 & $4,7 \%$ \\
\hline
\end{tabular}

Tabela 4 - valores obtidos para o grupo 4 do primeiro sujeito (dados de J.V. Schmicheck).

Os dados produzidos pelo Sujeito 1 atestam a variabilidade de produção em sua fala e, especialmente, o fato de que o sujeito produz tap, apesar de as descrições do inventário de sons do kreyòl afirmarem que esse som não existe na língua. O sujeito produz também a aproximante alveolar, que em línguas como o PB funciona como variante de /r/ e pode ocorrer nos mesmos ambientes que o tap.

Na produção deste sujeito, vê-se que não houve registro de consoantes laterais nos estímulos dissílabos, nem mesmo naqueles em que a lateral era esperada. Vê-se também que a maior parte das produções era de aproximantes, um som contínuo como as laterais, mas com frequências de formantes (F2 e F3, principalmente) mais altas do que as frequências de formantes das laterais.

Vejamos, agora, as produções atestadas para o Sujeito 2.

\begin{tabular}{|l|l|l|l|}
\hline \multicolumn{5}{|c|}{ Sujeito 2 - Grupo 1 - Dissílabos com a presença de /rl } \\
\hline \multicolumn{1}{|c|}{ Tipologia } & $\begin{array}{c}\text { Presença nas Três } \\
\text { Repetições }\end{array}$ & $\begin{array}{c}\text { Média de Duração Absoluta } \\
\text { em milissegundos (ms) }\end{array}$ & $\begin{array}{c}\text { Média de Duração Relativa } \\
\text { Segmento/Palavra }\end{array}$ \\
\hline Aproximantes & $77,8 \%$ & 81 & $16,6 \%$ \\
\hline Taps & $11,1 \%$ & 47 & $9 \%$ \\
\hline Taps Hibridos & $11,1 \%$ & 124 & $17,5 \%$ \\
\hline
\end{tabular}

Tabela 5 - valores obtidos para o grupo 1 do segundo sujeito (dados de J.V. Schmicheck). 


\begin{tabular}{|c|c|c|c|}
\hline \multicolumn{4}{|c|}{ Sujeito 2 - Grupo 2 - Dissillabos com a presença de /ll } \\
\hline Tipologia & $\begin{array}{c}\text { Presença nas Três } \\
\text { Repetiçōes }\end{array}$ & $\begin{array}{c}\text { Média de Duração Absoluta } \\
\text { em milissegundos (ms) }\end{array}$ & $\begin{array}{c}\text { Média de Duração Relativa } \\
\text { Segmento/Palavra }\end{array}$ \\
\hline Aproximantes & $100 \%$ & 84 & $18 \%$ \\
\hline
\end{tabular}

Tabela 6 - valores obtidos para o grupo 2 do segundo sujeito (dados de J.V. Schmicheck).

\begin{tabular}{|c|l|l|l|}
\hline \multicolumn{5}{|c|}{ Sujeito 2 - Grupo 3 - Trissilabos com a presença de /rl } \\
\hline Tipologia & $\begin{array}{c}\text { Presença nas Três } \\
\text { Repetições }\end{array}$ & $\begin{array}{c}\text { Média de Duração Absoluta } \\
\text { em milissegundos (ms) }\end{array}$ & $\begin{array}{c}\text { Média de Duração Relativa } \\
\text { Segmento/Palavra }\end{array}$ \\
\hline Aproximantes & $88,9 \%$ & 89 & $11,9 \%$ \\
\hline Taps & $11,1 \%$ & 76 & $9,6 \%$ \\
\hline
\end{tabular}

Tabela 7 - valores obtidos para o grupo 3 do segundo sujeito (dados de J.V. Schmicheck).

\begin{tabular}{|c|l|l|l|}
\hline \multicolumn{5}{|c|}{ Sujeito 2 - Grupo 4 - Trissílabos com a presença de II/ } \\
\hline Típologia & $\begin{array}{c}\text { Presença nas Três } \\
\text { Repetições }\end{array}$ & $\begin{array}{c}\text { Média de Duração Absoluta } \\
\text { em milissegundos (ms) }\end{array}$ & $\begin{array}{c}\text { Média de Duração } \\
\text { Relativa } \\
\text { Segmento/Palavra }\end{array}$ \\
\hline Aproximantes & $100 \%$ & 88 & $13,8 \%$ \\
\hline
\end{tabular}

Tabela 8 - valores obtidos para o grupo 4 do segundo sujeito (dados de J.V. Schmicheck).

O Sujeito 2, conforme apontam as Tabelas 5, 6, 7 e 8, não produziu lateral em nenhum dos contextos analisados, nem mesmo naqueles em que era esperada. Parece haver alguma substituição da lateral pelo tap, contrariando portanto a pergunta que este estudo colocava anteriormente, e que tocava na substituição do tap pela lateral. O máximo que se tem são as produções rotuladas "taps híbridos", ou seja sons cuja produção começa como a de um tap e termina como a de uma lateral. Tem-se, portanto, e mais uma vez, uma evidência clara da variabilidade de pronúncia na fala de um mesmo indivíduo.

Finalmente, os dados do Sujeito 4.

\begin{tabular}{|l|l|l|l|}
\hline \multicolumn{5}{|c|}{ Sujeito 4 - Grupo 1 - Dissílabos com a presença de /rl } \\
\hline Tipologia & $\begin{array}{c}\text { Presença nas Três } \\
\text { Repetições }\end{array}$ & $\begin{array}{c}\text { Média de Duração Absoluta em } \\
\text { milissegundos (ms) }\end{array}$ & $\begin{array}{c}\text { Média de Duração Relativa } \\
\text { Segmento/Palavra }\end{array}$ \\
\hline Aproximantes & $55,5 \%$ & 108 & $17,5 \%$ \\
\hline $\begin{array}{l}\text { Fricativas } \\
\text { posteriores }\end{array}$ & $44,5 \%$ & 133 & $17,6 \%$ \\
\hline
\end{tabular}




\section{$=\mathrm{T} R A M A=$}

\begin{tabular}{|l|l|l|l|}
\hline \multicolumn{5}{|c|}{ Sujeito 4 - Grupo 2 - Dissilabos com a presença de /II } \\
\hline \multicolumn{1}{|c|}{ Tipologia } & $\begin{array}{c}\text { Presença nas Três } \\
\text { Repetiçōes }\end{array}$ & $\begin{array}{c}\text { Média de Duração Absoluta } \\
\text { em milissegundos (ms) }\end{array}$ & $\begin{array}{c}\text { Média de Duração Relativa } \\
\text { Segmento/Palavra }\end{array}$ \\
\hline Aproximantes & $88,9 \%$ & 101 & $15,6 \%$ \\
\hline Laterais & $11,1 \%$ & 103 & $14,4 \%$ \\
\hline
\end{tabular}

Tabela 10 - valores obtidos para o grupo 2 do quarto sujeito (dados de J.V. Schmicheck)..

\begin{tabular}{|l|l|l|l|}
\hline \multicolumn{5}{|c|}{ Sujeito 4 - Grupo 3 - Trissilabos com a presença de /rl } \\
\hline \multicolumn{1}{|c|}{ Tipologia } & $\begin{array}{c}\text { Presença nas Três } \\
\text { Repetiçōes }\end{array}$ & $\begin{array}{c}\text { Média de Duração Absoluta } \\
\text { em milissegundos (ms) }\end{array}$ & $\begin{array}{c}\text { Média de Duração Relativa } \\
\text { Segmento/Palavra }\end{array}$ \\
\hline Aproximantes & $66,6 \%$ & 117 & $13,7 \%$ \\
\hline $\begin{array}{l}\text { Fricativas } \\
\text { posteriores }\end{array}$ & 22,3 & 149 & $15,8 \%$ \\
\hline Taps & $11,1 \%$ & 81 & $7,6 \%$ \\
\hline
\end{tabular}

Tabela 11 - valores obtidos para o grupo 3 do quarto sujeito (dados de J.V. Schmicheck).

\begin{tabular}{|l|l|l|l|}
\hline \multicolumn{5}{|c|}{ Sujeito 4 - Grupo 4 - Trissílabos com a presença de III } \\
\hline \multicolumn{1}{|c|}{ Tipologia } & $\begin{array}{c}\text { Presença nas Três } \\
\text { Repetiçōes }\end{array}$ & $\begin{array}{c}\text { Média de Duração Absoluta } \\
\text { em milissegundos (ms) }\end{array}$ & $\begin{array}{c}\text { Média de Duração Relativa } \\
\text { Segmento/Palavra }\end{array}$ \\
\hline Aproximantes & $25 \%$ & 94 & $11,8 \%$ \\
\hline Laterais & $75 \%$ & 105 & $11,2 \%$ \\
\hline
\end{tabular}

Tabela 12 - valores obtidos para o grupo 4 do quarto sujeito (dados de J.V. Schmicheck).

Os dados das Tabelas 9, 10, 11 e 12 evidenciam, uma vez mais, a variabilidade de produção na fala de um mesmo indivíduo. O Sujeito 4, porém, produz fricativas posteriores ${ }^{12}$, que os demais sujeitos não produziam, e apenas em contextos onde era esperado o tap. Por outro lado, produz laterais nos contextos em que eram esperadas. Produz também aproximantes. Convém notar que S4 apresentou problemas na leitura da narrativa, relacionados à pouca fluência, e que se refletiam em hesitações e longas pausas. A pouca fluência, porém, parece não ter sido um empecilho para que S4 realizasse taps e laterais em contextos onde eram esperados.

\section{DISCUSSÃO DOS DADOS E CONSIDERAÇÕES FINAIS}

Diante das análises acústicas das produções de cinco sujeitos, expostas na seção anterior, é possível fazer algumas generalizações sobre os resultados obtidos. A mais óbvia, e que fiz questão de frisar, é a variabilidade de produção das líquidas, de modo que há o registro da presença de taps, vibrantes, aproximantes, fricativas posteriores e taps híbridos na fala dos sujeitos.

\footnotetext{
12 Prefiro me referir, genericamente, a "fricativas posteriores", ao invés de tentar precisar o ponto de articulação desses sons - se velares, uvulares, faringais ou glotais - porque não dispomos de estudos articulatórios que nos permitam tal precisão. Cabe acrescentar que acusticamente a diferenciação do ponto de articulação de fricativas posteriores é tarefa difícil, porque a faixa de frequência na qual se estende o ruído das diversas fricativas é muito próxima. Daí a necessidade de estudos articulatórios.
} 


\section{$=$ TRAMA $=$}

Estes achados deixam claro o fato de que não há, propriamente, a substituição de uma categoria sonora por outra na fala dos aprendizes, mesmo que esses aprendizes tenham tido contato com o PB por aproximadamente um ano apenas e que a instrução formal que recebem dessa língua fosse ainda mais breve, na época da coleta dos dados.

Este é um dado importante, porque evidencia que não se trata de que os falantes de kreyòl não conseguem produzir o tap: eles não só conseguem como efetivamente produzem esse som. Entretanto, nem sempre o produzem no contexto esperado.

Outra generalização possível, a partir dos resultados da análise apresentada na seção anterior, é a de que existem sons intermediários a taps e a laterais: as aproximantes alveolares se enquadram nessa caracterização, já que ao mesmo tempo em que têm frequência alta de formantes - o que as aproxima de taps, mas as distancia de laterais - têm aspecto contínuo o que as aproxima de laterais. Os "taps híbridos" seguem pelo mesmo rumo: são intermediários a duas categorias na medida em que começam com a interrupção da energia de produção, mas terminam como um evento acústico contínuo.

Finalmente, há que se anotar o comportamento distinto entre os sujeitos: os comentários apresentados a propósito das tabelas na seção anterior evidenciam que nenhum dos quatro sujeitos cujas produções foram analisadas por Schmicheck (2018) se comportam da mesma maneira: um produz variantes que outro não produz, assim como um produz um som diferente daquele produzido pelos outros no mesmo contexto.

Como explicar esses fatos que os dados nos mostram? A variabilidade na produção das líquidas, e a consequente substituição não categórica do tap por algum outro som assemelhado podem ser resultado do fato de que, tendo apenas a categoria "lateral alveolar" na classe das líquidas, o kreyòl deixe espaço articulatório e acústico para que se produzam variações de [l], sem que essas variações sejam percebidas pelos falantes nativos de kreyòl. Colocando de outro modo: como o kreyòl tem apenas [l], é possível fazer um som mais breve, decorrente de uma rápida batida da ponta da língua nos alvéolos - o que configura o tap - sem que essa alteração na produção resulte numa categoria perceptivelmente distinta de [l] para os falantes nativos de kreyòl. Já no caso do PB a situação é outra: como o PB tem duas categorias, [r] e [l], e essas categorias promovem distinção de sentido entre palavras - segundo já se comentou neste estudo - a "troca" de uma categoria pela outra caso, e.g., a oclusão que a ponta da língua promove ao encontrar os alvéolos dure mais do que o esperado para a produção do tap, os falantes nativos de PB percebem a diferença na produção.

Isto porque o PB tem duas categorias sonoras e o kreyòl apenas uma. Assim sendo, nós podemos promover menor variabilidade articulatória do que os falantes de kreyòl. Produzindo tap ou lateral, eles perceberão os dois sons como uma única categoria, /I/.

Voltando à questão do ensino: os dados aqui expostos sugerem ser inócuo considerar que haitianos "não conseguem" produzir [r] e, portanto, precisam aprender a fazer isso. Eles produzem o tap. É necessário, porém, estabelecer essa categoria, que os haitianos não têm em sua língua materna, quando aprendem PB.

Se retornarmos, agora, à concepção da língua como um SAC, podemos fazer a seguinte consideração: até o momento imediatamente anterior àquele em que tomaram contato com o PB, o sistema sonoro que os haitianos detinham estava num ponto de equilíbrio. No momento em que os haitianos começam a adquirir PB, o novo sistema promove um estado de caos e, consequentemente, distancia do ponto de equilíbrio o sistema sonoro dos haitianos. Podemos esperar que o equilíbrio se restabeleça quando, finalmente, os haitianos estabelecerem duas categorias de consoantes líquidas em suas falas. Desta forma, podemos pensar em três momentos, genericamente falando, pelo qual se desenvolve o processo de aquisição do PB: 


\section{$=$ TRAMA $=$}

- Momento 1: equilíbrio do sistema (sons do kreyòl)

- Momento 2: distanciamento do sistema a partir do equilíbrio (aquisição do PB por falantes nativos de kreyòl)

- Momento 3: equilíbrio do sistema (sons do kreyòl + sons do PB)

Os sujeitos cujas produções comentamos estariam, portanto, no que estamos chamando de "momento 2" do processo de aquisição do PB.

Para que o sistema atinja novamente um ponto de equilíbrio - chegue ao "momento 3", como estamos chamando -, o sistema sonoro produzido pelos estará sujeito a uma série de variáveis extralinguísticas, que vão desde o tempo de exposição ao PB, bem como a interação com falantes nativos de PB, coocorrendo com a interação com falantes nativos de kreyòl, até seu grau de escolaridade e até a sua vontade de ser identificado como um falante de PB. $O$ peso de cada uma dessas variáveis varia por hipótese varia, de indivíduo para indivíduo.

À guisa de conclusão, cabe comentar que, do que se expôs aqui, deve restar claro que o processo de aquisição de uma língua estrangeira, mormente no que toca ao seu aspecto sonoro, não se resume à simples "troca" de um som por outro e no fato de os sujeitos não conseguirem produzir um som que existe na língua-alvo, mas não em sua língua materna. Como procurei mostrar, as produções dos aprendizes envolvem uma grande variabilidade que se relaciona, em última instância, ao processo de estabelecimento das categorias sonoras da língua-alvo. E, se assumimos a língua como um SAC, reconhecemos necessariamente que há diversas variáveis extralinguísticas que coocorrem e que exercem influência sobre o processo de aquisição. Por isso, muito mais do que simples exercícios de pronúncia que consistem em fazer os alunos repetirem o que ouvem, é preciso pensar em métodos como o proposto por Alves et al. (2017), a que eu me referia no início deste estudo.

\section{REFERÊNCIAS}

ALBANO, E. C. O gesto e suas bordas - esboço de fonologia acústico-articulatória do português brasileiro. Campinas: Mercado de Letras/FAPESP, 2001.

ALVES, U.K.; BRISOLARA, L.B.; PEROZZO, R.V. Curtindo os sons do Brasil - Fonética do Português do Brasil para Hispanofalantes. Lisboa: Lidel, 2017.

BECKER, M.R. Inteligibilidade da lingua inglesa sob o paradigma de língua franca: percepção de discursos de falantes de diferentes L1s por brasileiros. Tese de doutorado. Inédita. UFPR. 2013.

BECKNER, C. et al. Language is a complex adaptative system: position paper. Language Learning, v. 59, n. 1, p. 1-26, dez. 2009.

CADELY, J.R. Haiti: the politics of language. Journal of Teaching and Education, 1(3):389-394, 2012.

CADELY, J. R.. Les sons du Creòle haitien. The Journal of Haitian Studies, 9 (2): 4-41, 2004.

CELCE-MURCIA, M.; BRINTON, D.M.; GOODWIN, J.M.; GRAINER, B. Teaching pronunciation: a course book and reference guide. Cambridge: Cambridge University Press, 2010.

CHAN, S. Complex Adaptative Systems. Research Seminar in Engineering Systems. October 31, 2001/November 6, p. 1-9, 2001.

DOVE, L. How does a forest fire benefit living things? DISPONIVEL em https://science.howstuffworks.com/environmental/green-science/how-forest-fire-benefit-living-things-2.htm. ACESSO em 18/02/2019.

MAJOR, R. C. Transfer in second language phonology. In: EDWARDS, J. G. H; ZAMPINI, M. L. Phonology and Second Language Acquisition. Philadelphia: John Benjamins, 2008.

SCHMICHECK, J. V. Produção de taps e laterais do PB por falantes de kreyòl. Relatório de Pesquisa de Iniciação Científica. Inédito. Universidade Federal do Paraná. 2018.

SILVA, A.H.P. Caracterização acústica de [r], [r], [l] e [ $\Lambda$ ] nos dados de um informante paulistano. Cadernos de Estudos Linguísticos, 37:51-6, 1999. 
SILVA, A. H. P. As fronteiras entre fonética e fonologia e a alofonia dos róticos iniciais em PB: dados de dois informantes do sul do país. Tese de doutorado. Inédita. Universidade Estadual de Campinas. 2002.

Silva, A.H.P. Uma ferramenta para o ensino do acento primário do PB para falantes nativos do crioulo haitiano. Organon, 30 (58): 175-191, 2015.

TARDIEU, G.M. Gramè Kreyòl. Kopivit-Laksyon Sosyal, 2013.

Recebido em 18-02-2019.

Aceito em 21-02-2019. 